\title{
SOBRE A CLÍNICA DA PSICANÁLISE DE ORIENTAÇÃO LACANIANA: DOS IMPASSES DA SEXUAÇÃO À INVENÇÃO DO PARCEIRO-SINTHOMA
}

Tania Coelho dos Santos

Pós-doutorado no Departamento de Psicanálise de Paris VIII; professora associada II do Programa de PósGraduação em Teoria Psicanalítica da UFRJ; membro da Associação Mundial de Psicanálise e da Escola Brasileira de Psicanálise; presidente da Associação Núcleo Sephora de Pesquisa; pesquisadora com bolsa de produtividade em pesquisa nível 1C.
RESUMO: Com base na releitura lacaniana da sexualidade, vamos desenvolver nossa tese sobre o laço íntimo entre sexuação e invenção. A última teoria do real é condensada na fórmula que preside o último ensino de Lacan: "não há relação sexual". O sintoma é a única infração à regra de que não há simbólico no real. As posições subjetivas masculina e feminina são sintomas, suplências da relação sexual que não existe. Retomando os marcos principais do pensamento freudiano sobre a sexualidade à luz do último ensino de Lacan, vamos demonstrar a articulação entre o ato da invenção e gênese do parceiro-sinthoma.

Palavras-chave: Sexuação, invenção, Nome do pai, objeto a, real.

ABSTRACT: About the Lacanian oriented psychoanalysis clinic: from the sexual dead-lock to the invention of the symptom-partner. After we have pursued the Lacanian view of sexuality, we shall devellop our thesis on the intimate bond between sexuation and invention. The last theory of reality sums itself up in the formula that directs the last teaching of Lacan: "there is no sexual relation". The symptom is the only exception to the rule that states: the real is symbol-less. The male and female subjective positions are symptoms, supplements in the unexisting sexual relation. By resuming the main landmarks of Freudian thought on sexuality, in light of Lacan's last teaching, we shall demonstrate the articulation between the act of invention and the genesis of symptom-partner.

Keywords: Sexuation, invention, Name of the father, object a, real. 


\section{INTRODUÇÃO AO PROBLEMA E ESBOÇO DE UMA SOLUÇÃO}

Em seu comentário ao relato de Freud (1900/1972) do "Sonho de injeção em Irma”, Lacan (1954-1955/1978) destaca a dificuldade do criador da psicanálise em formular a causa da neurose. Depois de percorrer um desfiladeiro de identificações imaginárias com os médicos que fracassaram em decifrá-la, Freud, em seu sonho, é confrontado com o surgimento do significante puro "trimetilamina", isolado da cadeia. Segundo Lacan (1954-1955/1978), esse novo nome circunscreve o advento de um saber inédito: o desejo sexual inconsciente. Como já desenvolvi em outro trabalho (COELHO DOS SANTOS, 2005a), segundo Lacan, esse sonho interpreta o desejo de Freud. Esse sonho efetua a mudança na posição subjetiva de Freud, desde a suposição de saber feita à medicina em direção à invenção de um saber novo. A invenção da psicanálise é a interpretação do desejo de Freud, o saber sobre a causa sexual da neurose. O inventor do inconsciente cumpre a promessa feita a si mesmo, na casa onde teve esse sonho: "Você supõe que algum dia uma plaqueta de mármore será colocada na casa, inscrita com essas palavras: nesta casa, em 24 de julho de 1895 o segredo dos sonhos foi revelado a Sigmund Freud" (FREUD, 1900/1972, p.130). Em que sentido empregamos aqui o termo 'invenção'?

Nesse artigo, depois de percorrermos a releitura lacaniana da sexualidade, vamos desenvolver nossa tese sobre o laço íntimo entre sexuação e invenção. Ela é baseda na última teoria do real e que se condensa na fórmula que preside o último ensino de Lacan (1972-1973/1984): "não há relação sexual”. Essa abordagem, que faz da castração o axioma fundamental, trata o sintoma como a única infração à regra de que não há simbólico no real. Nessa perspectiva, as posições subjetivas masculina e feminina são sintomas, isto é, suplências da relação sexual que não existe. Para construir essa abordagem, vamos retomar os marcos principais do pensamento freudiano sobre a sexualidade à luz do último ensino de Lacan. Queremos demonstrar nossa hipótese de uma articulação entre o ato da invenção e a gênese da solução sintomática na vida amorosa: o parceiro-sinthoma.

\section{BREVE RELEITURA DE FREUD À LUZ DO ÚLTIMO ENSINO DE LACAN}

Freud descortinou um horizonte inteiramente novo sobre a natureza da sexualidade humana. Revelou sua origem autoerótica, dispersa nas zonas erógenas do corpo. Problematizou a constituição da identificação sexuada e do objeto do desejo, mostrando que dependem da distribuição da libido nos vasos comunicantes da relação narcísica com o semelhante, do complexo de castração e do complexo de Édipo. Sem o mecanismo psíquico do recalcamento da sexualidade autoerótica, não existe homem, nem mulher, nem desejo inconsciente. 
A dissimetria do Complexo de Édipo masculino e feminino evidenciou que não existe um saber natural ou instintivo sobre a diferença sexual. Ela não tem um sentido universal. O sentido sexual provém do recalcamento que é um processo interpretativo, escandido em dois tempos, que se efetua sobre o afeto do encontro traumático com o sem-sentido da diferença sexual. Chamamos de castração, o advento da lógica opositiva entre ter e não ter o pênis, que vem a ser a consequência psíquica da diferença anatômica entre os sexos. Essa interpretação da dissimetria entre os sexos depende dos efeitos de retroação significativa de um segundo encontro com o real sem sentido da diferença anatômica que, só então, confere sentido ao primeiro encontro. Freud enlaça o complexo de castração - encontro com o real traumático da diferença sexual — ao complexo de Édipo que é a interpretação dessa diferença como castração da mulher. Para o menino, o pai é o agente da castração e, por essa razão, tem medo dele. A menina se considera privada do pênis pela mãe e, ressentida, desloca seu amor para o pai de quem espera uma compensação. Freud (1925/1977) explica a sexuação masculina e feminina com base nas consequências psíquicas da diferença anatômica entre os sexos. As posições subjetivas do homem e da mulher surgem no rastro da alternativa entre ter e não ter o pênis.

Proponho que o laço entre sexuação e invenção remete ao seguinte: essa alternativa que captura a sexualidade infantil precisa ser ultrapassada na entrada da puberdade. Existe um salto lógico entre a significação da diferença sexual como alternativa entre ter e não ter o pênis e as identificações sexuais pubertárias, baseadas no ideal do eu. Esse salto, na linguagem freudiana, é o de superar a ignorância da vagina. Para Lacan, trata-se do surgimento da significação do falo. O passo para Lacan é lógico:

"O fato de que um certo pedagogo formulou que não existe um verdadeiro acesso aos conceitos, senão a partir da puberdade, mereceria que acrescentássemos nosso olhar, que metêssemos nosso nariz aí. Há mil traços sensíveis de que o momento em que começa verdadeiramente o funcionamento do conceito (...), poderia receber uma outra abordagem em função de um laço a ser estabelecido com a maturação do objeto a, tal como eu o defini, na puberdade." (LACAN, 1962-1963/2004, p.299300, tradução nossa)

Foi em termos de maturação do objeto a, com a promoção do falo na relação entre os sexos, que Lacan traduziu o que Freud chamou de "reencontro com o objeto" na puberdade. Admito, por hipótese, que a significação do falo é responsável pelo aparecimento do conceito e requer o ultrapassamento das consequências psíquicas da diferença anatômica entre os sexos. É preciso que entre em jogo a função essencial do vazio para que se possa entrar no univer- 
so dos semblantes — isto é, dos papéis sexuais em jogo na encenação da vida amorosa - por uma via diferente do imaginário.

As manobras defensivas histéricas e obsessivas retratam o impasse diante do vazio. Traduzem o fracasso do lado feminino e do lado masculino diante dessa ultrapassagem lógica do complexo de castração, no momento do "reencontro com o objeto" (FREUD, 1905/1972). É nesse terreno que podemos verificar a importância central, mas também os limites do complexo edipiano na superação da interpretação infantil da diferença sexual. Tornar-se homem ou mulher requer ir além do Édipo, retornando ao campo da pulsão. Freud (1925/1977) se refere, claramente, ao "complexo de masculinidade" e à “inibição” como respostas histéricas, isto é, respostas aversivas à diferença sexual. Freud (1912/1970) desenvolveu também a hipótese de que a "tendência universal à depreciação na esfera do amor", é a estratégia defensiva do obsessivo. Consiste em dividir o conjunto das mulheres em dois grupos: as santas e as de má reputação. Freud (1925/1977) indica a herança do útero como saída do impasse da histeria. Muitos psicanalistas acreditam que Freud confunde a mulher com a mãe. Penso que isso não é evidente. Se, interpretamos a herança do útero como a descobertada da vagina na puberdade, podemos aproximá-la do que Lacan conceitou como entrada em funcionamento do falo. Para superar a neurose obsessiva, ainda segundo Freud (1937/1975), seria preciso amenizar a rivalidade inconsciente com outro homem que alimenta a ameaça de castração. Essa superação da rivalidade não é possível se não se vai além do imaginário da castração. Em outro trabalho (COELHO DOS SANTOS, 2006) desenvolvi uma extensa argumentação acerca da invenção lacaniana do real. Destaquei que, segundo esse autor, essa invenção ultrapassa a concepção energética da pulsão de morte. Interpretei a invenção do real como o passo adiante do analisando Lacan, em sua transferência com Freud. A invenção do real é uma mudança na posição subjetiva de Lacan em consequência da queda da suposição de saber feita a Freud.

Em seu Seminaire XVI, D’un Autre à l'autre, Lacan (1968-1970/2006a) redefine as estruturas histérica e obsessiva com base nas estratégias defensivas feminina e masculina para colocar à distãncia o gozo. Em seu Seminaire VII, L'éthique de la psychanalyse, Lacan (1959-1960/1986) havia definido o objeto do gozo como a Coisa (das Ding). A novidade agora é a seguinte: o Falo $(\phi)$ e a Coisa (das Ding) são equivalentes em seu valor de referentes absolutos do gozo, respectivamente, para o homem e para a mulher. A Coisa (o gozo) e o Falo (o símbolo) são irrepresentáveis. Por essa razão, o homem e a mulher precisam fazer um esforço a mais para erigir o Ideal do eu, como conviria ao seu sexo. Existe um passo de sentido (pas de sens), um passo lógico a dar para situar-se no universo dos semblantes, pois tanto o símbolo quanto o objeto são exteriores ao campo do saber inconsciente. 
A posição subjetiva histérica é essencial para que haja regulação do excesso conforme o princípio do prazer. Ela coloca o gozo em ordem, na medida que o eleva ao absoluto. Lacan (1968-1969/2006a) afirma que ela é uma boa teórica, pois desvela a estrutura lógica da exclusão do gozo, ao preço de renunciar ao usufruto. Elevando o objeto ao absoluto, ela não o encarna como mulher. No lugar da descoberta da vagina, o fato de não ter o falo se reduz a um desejo insatisfeito. O obsessivo, por sua vez, recusa-se a encarnar o símbolo. Ele não quer ser tomado pelo mestre, ele não pode ser o mestre. Ele supõe saber ao mestre, pois acredita que este sabe o que ele quer. De modo análogo, a histérica se refere à outra mulher. Ela não consente em ser o objeto causa do desejo. Ela acredita que há outra mulher que sabe o que é preciso para sê-lo. A outra mulher é o sujeito suposto saber para a mulher histérica. O inconsciente como desejo de saber é uma barreira que impede o acesso ao inconsciente real. Somente quando a função do símbolo-falo é articulada à inexistência de um representante da mulher, veremos surgir a função do vazio como causa. É essa operação lógica que permite elevar a dissimetria entre os sexos à dimensão do conceito. Não existe acesso ao conceito sem a invenção singular, isto é, o ato de nomeação que refunda o sujeito, o código e a língua. Nomeação, sexuação e invenção são operações lógicas da mesma natureza.

Segundo Freud (1937/1975), ao término de uma análise, a solução dos impasses da sexuação permitiria ao sujeito conciliar-se com a sua feminilidade. Como Lacan (1968-1969/2006) também eleva o falo à dimensão de referente absoluto da identificação para o homem, podemos renovar nossa interpretação da dificuldade masculina de dissolver a ameaça de castração — um impasse da sexuação — à luz dessa perspectiva. Formulo, por hipótese, que somente quando homens e mulheres podem superar o repúdio desses referentes absolutos do gozo, consentirão em encarnar seus papéis sexuais. Para encarná-los é preciso recriá-los em conjunção ou disjunção com os semblantes de uma dada civilização. Mais além dos impasses da sexuação na neurose se poderia esperar, então, alguma felicidade no amor entre um homem e uma mulher.

Em seu Seminaire XX, Encore, Lacan (1972-1973/1984) parte do axioma de que não há relação sexual para trazer ao centro de sua teoria da constituição subjetiva as respostas, necessariamente distintas, que homem e mulher inventam para suprir essa ausência. Se a psicanálise, em seu primeiro ensino, foi concebida como uma ética do desejo, seria preciso retomá-la agora no âmbito de uma prática de responsabilização pelo sintoma. O amor entre os sexos não é idílico, mas também não é necessariamente infeliz. Quando se pode dar um passo lógico com respeito à castração, a diferença se torna a condição do gozo e não apenas o impedimento. A responsabilidade sexual implica uma resposta inovadora, inventiva, diante da inexistência da relação sexual. Ela refunda a parceria amorosa graças à invenção 
do parceiro-sinthoma, mais além da castração. Avancei algumas proposições para renovar o debate sobre o tema e passo a fundamentá-las um pouco mais, percorrendo sem exauri-los os principais marcos do retorno de Lacan a Freud.

\section{PRIMEIRA FORMALIZAÇÃO DA SEXUALIDADE:}

\section{SUJEITO DO SIGNIFICANTE, OBJETO A E FANTASMA}

O primeiro ensino de Lacan retoma a descoberta freudiana das relações entre a sexualidade e o inconsciente, revelando sua dependência da linguagem. Essa abordagem confere primazia ao simbólico, estrutura de linguagem que mortifica o corpo, reduzindo-o ao significante. A linguagem, por essa razão, é a condição do inconsciente. O saber inconsciente, por conseguinte, é o discurso do Outro. O corpo, nessa vertente, é uma imagem constituída por meio do significante. O encontro com a imagem no espelho precipita na criança uma reação de júbilo. Seu corpo, que era experimentado até esse momento como fragmentado e autoerótico, unifica-se no estádio do espelho provocando o narcisismo, isto é, a identificação com a imagem de si totalizada.

$\mathrm{Na}$ experiência analítica - porque ela se dá no campo da fala e da linguagem - o gozo imaginário, narcísico, dá lugar ao desejo metonímico. No primeiro ensino de Lacan, a experiência analítica consiste numa operação metafórica: a de transportar a literalidade do gozo imaginário para o registro simbólico. Para todo sujeito, consequentemente, a identificação ao ideal do seu sexo aponta para um horizonte-miragem em perpétuo deslocamento. O desejo, resíduo ineliminável da passagem do imaginário ao simbólico, é um entrave a essa satisfação. Não pode haver felicidade no amor se o desejo é, por definição, um desejo fundamentalmente insatisfeito. A saída encontrada por Lacan será a formalização de uma nova teoria do objeto, que não mais o reduz ao imaginário. A invenção do objeto a, causa do desejo, lança uma nova luz também sobre a natureza do ideal do eu.

O ideal do eu, que se funda no campo da fala e da linguagem, não pode se reduzir à identidade da imagem do espelho. Lacan em seu Seminaire X (19621963/2004), intitulado “La angloise”, realiza uma mudança decisiva no seu ensino quando reconhece essa irredutibilidade. De um lado, porque há um resto autoerótico do narcisismo, um objeto sem imagem, a causa do desejo. De outro, porque o olhar provém do ideal do eu, ponto de onde o sujeito é visto, não pode ser representado no campo imaginário. No segundo momento do seu ensino (LACAN, 1964-65/1973) em seu Seminário XI, dedica-se a formalizar esse objeto causa do desejo, articulando-o de um modo interiamente novo ao inconsciente estruturado como a linguagem que engendra o sujeito de desejo. O sujeito ainda é definido como o que "um significante representa para outro significante" mas a ênfase recai sobre o sentido que se produz e que se perde. Ao 
sentido evanescente articula-se o movimento de abre e fecha das zonas erógenas do corpo. Corpo e linguagem participam de uma mesma estrutura de corte. O objeto do gozo, num movimento homólogo ao do sujeito do significante, surge e desaparece nas zonas erógenas.

O conceito de fantasma $(\$<>$ a) em Lacan (1964-65/1973) articula as duas vertentes do inconsciente: a estrutural e a pulsional. O sujeito na linguagem é um sujeito dividido (\$), isto é, identificado aos significantes do Outro. Quando o apreendemos ao nível do gozo do corpo ele não é nem mesmo ainda um sujeito, pois se reduz a um objeto parcial para o desejo do Outro. O fantasma é o conceito que permite abordar essas duas vertentes do inconsciente em jogo na experiência analítica: a do desejo a ser decifrado e a do gozo a ser extraído do corpo afetado passivamente pelo significante. O gozo informe do corpo, ao ser extraído pela fala, localiza-se num objeto parcial. O fantasma formaliza a conjunção e a disjunção entre o desejo e o gozo. A superação dos impasses da sexuação, na perspectiva adotada no Seminário XV ((LACAN, 1967-1968) depende do atravessamento do fantasma no processo analítico. Separar \$ e a teria o efeito didático de provocar um salto lógico: o advento do desejo do analista. O desejo do analista é uma nova forma de amar? Se isso é verdade, que espécie de felicidade haveria nesse novo amor?

É preciso observar que o fantasma é unissex. É um aparelho que circunscreve o parceiro sexual com base no gozo relativo a um objeto parcial. Ao atravessálo, o sujeito verifica sua dependência do significante mestre que ele extraiu do campo do Outro, mas também se revela sua fixação a um encontro contingente com um objeto no campo do autoerotismo. Essa formalização do fantasma, apesar de trazer um avanço com relação à clínica do signficante, não nos oferece uma orientação sobre o que se pode esperar de uma análise quanto à relação entre os sexos. Ela parece isolar os parceiros sexuais na felicidade da satisfação autoerótica de cada um. Cada um com seu pequeno objeto mais-de-gozar! Essa solução inclui o risco de uma saída cínica ao término de uma análise. Lacan indica nesta época que a queda do sujeito suposto saber na transferência analítica, somente dá lugar ao desejo do analista ao preço de um desmentido. Oferecer-se como semblante do sujeito suposto saber para alguém, depois de ter feito a experiência da queda de toda suposição de saber ao inconsciente, não é uma saída do processo analítico fácil de justificar. A invenção do dispositivo do passe para verificar o final da análise e a fundação de sua Escola nessa mesma época, foram recursos para enfrentar os impasses e riscos da descrença pós-analítica no saber.

O desejo do analista vai ceder seu lugar na teorização de Lacan (19691970/1991) sobre os efeitos de uma análise, ao discurso do analista. Nessa nova perspectiva, o sintoma começa a superar a importância que ele havia concedido ao fantasma. Os quatros discursos, formalizados no Seminaire XVII intitulado 
“L'envers de la psychanalyse”, desenvolvem uma fórmula que reúne o inconsciente estruturado como a linguagem (S1, S2) e o inconsciente como gozo pulsional, condensado na fórmula do fantasma $(\$<>a)$. Essa conjunção entre as duas vertentes do inconsciente é o sintoma. A via do sintoma é também a da moral sexual civilizada e doença nervosa moderna, que Lacan (1966, p.855-878) reduz a uma fórmula: “o sujeito sobre o qual a psicanálise opera só pode ser o sujeito da ciência”. A lógica do recalque não dá lugar apenas a uma subtração. Freud (1938/1975) já havia articulado o mal-estar na civilização à produção de um excesso pelo supereu. Observou que quanto mais se renuncia à satisfação pulsional, mais se é levado a renunciar. Lacan (1963/1966) deduziu desse imperativo superegóico que existiria uma satisfação pulsional com a própria renúncia. Para abordar a estrutura do sintoma é preciso situar o dispositivo analítico na lógica da modernidade como produção de um excesso, um gozo-a-mais, lucro, mais-valia. O supereu na era do capitalismo engendra a satisfação com a perda, o gozo da entropia. Nessa perspectiva, o sintoma, o laço social e o discurso da modernidade devem ser tomados como estruturalmente equivalentes. Afinal, o que é próprio ao modo de produção capitalista não é a renúncia ao gozo e sim a promessa, como teria revelado Pascal (apud LACAN, 1968-1969/ 2006a), de "uma infinidade de vidas, infinitamente felizes".

Ao promover o sintoma, a sexuação como sintoma do homem e da mulher vem ao primeiro plano, como se verá no seminário seguinte. O sintoma será a grande ferramenta que Jacques Lacan nos legou para abordar os impasses da sexuação. Para formalizar o aparelho que comanda o funcionamento subjetivo na modernidade, ele (1969-1970/1991) reduziu o sujeito a quatro letras: S1 (significante mestre), S2 (o saber), \$ (o sujeito dividido pelo significante) e o objeto a (lucro, mais, valia, mais-de gozar). Essas quatro letras se arranjam de acordo como um tetraedro, e se as fazemos girar um quarto de volta no sentido horário, obtemos quatro permutações que correspondem aos quatro discursos. São quatro lugares. Na linha superior, encontram-se o do agente e o do saber. Na linha de baixo, temos o do trabalho e o da produção. Em seu Seminário XVI (LACAN, 1968-1969/2006a) esclarece que se trata dos lugares do Nome do pai, do desejo da mãe, do sujeito e da criança. Respectivamente, conforme os exibimos abaixo, os quatro discursos são: o discurso do mestre, o da histérica, o do psicanalista e o da universidade.

O discurso que funda a civilização é o discurso do mestre. A religião, forma primeira do Direito, enuncia as verdades inaugurais em nome do significante mestre (S1), isto é, Deus. O discurso do mestre exprime-se nas escrituras sagradas na forma oracular, imperativa, arbitrária e infundada. O advento da ciência, matriz da modernidade, coloca o saber (S2) em questão. Essa é também a prerrogativa do discurso da histérica. Ela é o sujeito dividido pelo significante mestre (\$) 


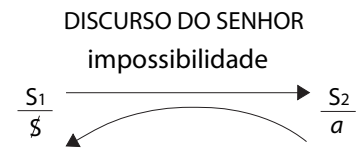

se esclarece por regressão do

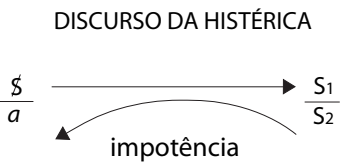

Os lugares são de

$\frac{\text { o agente }}{\text { a verdade }} \quad \frac{\text { o outro }}{\text { a produção }}$
DISCURSO DA UNIVERSIDADE

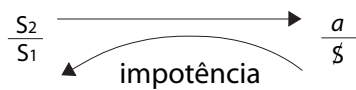

se esclarece por "progresso" no

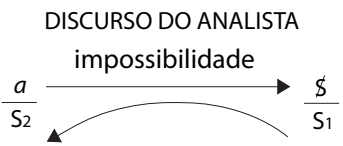

Os termos são

S1 o significante (sê-lo) mestre

S2 o saber

$\$$ o sujeito

$a$ o mais-gozar

que interroga e expõe as falhas do seu saber (S2). As histéricas mostram que os mestres não sabem tudo. Freud, o primeiro psicanalista, foi também o primeiro a não cair nessa armadilha. Antes dele o saber psiquiátrico revelou-se impotente em decifrar o enigma do sintoma histérico. Uma falsa anatomia dava forma às paralisias histéricas. Coube a Freud elucidar a lógica dessa falsa anatomia, revelando que o sintoma obedecia às leis da linguagem e podia ser suprimido pela interpretação de seu sentido inconsciente. Lacan (1968-1969/2006a), baseado na aproximação entre Freud e Marx que Althusser promoveu, demonstra que o sintoma é uma estrutura que diz respeito às relações dos homens modernos com o gozo. A satisfação que se obtém com o usufruto das funções naturais do corpo biológico não é a mesma que aquela que se extrai graças ao seu ciframento no sintoma. Essa outra anatomia é a causa (objeto a) de uma outra satisfação, um lucro, uma mais-valia, que quando é extraída se acumula à margem do funcionamento natural.

Descrevemos até esse momento o discurso do mestre, o da histérica e o do psicanalista. O que define o advento de uma nova era, a contemporaneidade, é a entrada do saber no mercado. Surge o discurso universitário que se caracteriza por colocar o saber (S2) em lugar de agente. Ele nasce com o rebaixamento do saber ao diploma universitário. O saber tornar-se-ia, tal como Lacan (1968-1969/2006) antecipa, uma mercadoria que se compra e se vende, levando à dissolução do laço singular de um sujeito ao saber inconsciente. O discurso universitário conduziria ao que se vê hoje: a sociedade da informação O saber está por toda parte. Entretanto, não se sabe mais onde reconhecer a verdade.

Os quatro discursos reúnem todos os elementos da primeira formalização da sexualidade. Os discursos, sintomas e laços sociais têm uma mesma estrutura. 
São formações de compromisso entre desejo e gozo. São semblantes. Realizam a conjunção e a disjunção entre desejo (identificação) e gozo (fantasma/pulsão). Haveria algum discurso que não fosse do semblante? Se a sexuação é semblante, a sexualidade nada tem a ver com o real? Essa questão é trabalhada no Seminaire XVIII (LACAN, 1971/2006b) “D’un discours qui ne serait pas du semblant”. Neste seminário, Lacan avança a seguinte proposição. A identidade de gênero é somente o que se exprime por mio de dois termos: o homem e a mulher. Na gênese dessas identidades, o que acontece na infância só tem importância a partir do fato de que os seres humanos estão destinados a dividir-se em homens e mulheres na idade adulta. Como não existe a relação sexual que conviria à espécie humana, o que define o homem é sua relação à mulher e, inversamente. Essas definições somente podem ser extraídas da experiência falante completa, que inclui as instituições nas quais elas se exprimem, isto é, o casamento. Para o menino, trata-se na idade adulta de bancar o homem. É quase etológico. O macho é o agente da corte que visa capturar o interesse da fêmea. O que preside a relação entre os sexos é da ordem do semblante, isto é, do discurso. O discurso, o semblante, impõe ao gozo um envelope: o princípio do prazer. É o contrário do acting-out, a encenação, por exemplo, da paixão. O discurso permite que haja um gozo a mais (Merlust) daquilo que é impossível ao ato sexual. O falo é o gozo sexual solidário do semblante. Logo, a identificação sexual não consiste em acreditarse homem ou mulher, mas em dar-se conta de que para os meninos existem as mulheres e para as meninas existem os homens. O importante é que para os homens, a mulher é o falo e isso os castra. Para as mulheres, o homem é o falo. O que as castra é o fato de que somente podem ter acesso ao órgão sexual que o falo simboliza.

O real do gozo sexual será definido nessa época como o próprio falo, equivalente ao Nome do pai. Logo, nesse momento do ensino de Lacan não há outro gozo, somente o do semblante. Para o homem, a mulher é a hora da verdade porque ela pontua a equivalência do gozo com o semblante. A mulher melhor que ninguém sabe que o gozo é do semblante. Se os sexos são equivalentes na dimensão do discurso são, entretanto, distintos na prova de verdade que a mulher representa para o homem. A prova de verdade é a única coisa que pode conferir um lugar à conjunção entre semblante e gozo. Minha conclusão é a seguinte: a palavra da mulher é o que há de mais real para um homem. Esse é o ponto mais próximo de um discurso que não seria do semblante. No Seminário RSI (LACAN, 1974-1975, p.66-67), define-se a relação do homem com sua mulher conforme se segue:

“...uma mulher na vida de um homem, é qualquer coisa na qual ele acredita, ele crê que existe uma, algumas vezes duas, ou três, é bem aí, aliás, que é interessante, pois 
ele pode acreditar numa apenas. Somente, a isso, à fragilidade desse crer nisso (y), se reduz, manifestamente, o fato da não relação sexual, tão facilmente recortado por toda parte, eu quero dizer que ele se recorta. Não resta dúvida, quem quer que venha nos apresentar um sintoma, crê nisso (y)."

Dado que para a psicanálise, a questão da origem se reduz ao mito do assassinato do pai primordial, o gozo é estruturado como impossível. Excluída a figura mitológica do pai que gozava de todas as mulheres, não haveria nenhum outro gozo senão o do semblante.

\section{SEGUNDA FORMALIZAÇÃO DA SEXUALIDADE: O AXIOMA DA NÃO-RELAÇÃO SEXUAL}

O ensino de Lacan (1972-1973/1984), no Seminário XX, inverte a perspectiva do primeiro ensino. Na primeira formalização, a primazia é do significante que mortifica o gozo, deixando como resto o objeto a. O ponto de partida agora é o gozo de lalíngua. Sua linguística, Lacan esclarece, é a linguisteria do ser falante que fala, mas não sabe o que diz. Em seu primeiro ensino, graças ao modelo linguístico, Lacan formalizara o sujeito como um efeito metafórico do significante do Nome do pai. O sujeito era, então, a própria significação fálica (\$), que se produzia quando o significante paterno substituía a criança/falo, como objeto do desejo da mãe. Em seu segundo ensino, como demonstramos, o sujeito se define por meio do discurso que condensa a estrutura significante (S1-S2) e o fantasma $(\$<>\boldsymbol{a})$. Observe-se como, lentamente, Lacan caminhou na direção de uma significantização do gozo. Finalmente, reduz o gozo ao seu semblante, isto é, ao falo, significante da diferença sexual.

Nessa nova teorização, sujeito do significante (S1-S2) e gozo do fantasma $(\$<>\boldsymbol{a})$ são formalmente reduzidos ao ser falante, uma insígnia (S1, a). O ser falante é um corpo vivo atravessado pela linguagem. A língua, depois do Seminário $X X$ não é apenas um aparelho que mortifica o gozo, mas também é algo que o vivifica. A língua aparelha o gozo do corpo, isto é, aparelha o sujeito para gozar do corpo por meio do sinthoma. O sinthoma (S1/a) é uma maneira de gozar do próprio corpo.

O real, definido até então como impossível, nesse momento, circunscreve-se ao mal-entendido entre os sexos. Como não há relação sexual, então, também não existe equivalência entre os sexos. O gozo, nessa nova formalização, se faz representar pelo falo, pelo Nome do pai e pelo resto, o objeto a. São três nomes da lei que regula o gozo segundo o princípio do prazer. O real, por sua vez, não é o gozo regulado. O real é sem lei. Ele se apresenta como um enxame de significantes puros, sem encadeamento, na experiência inaugural do encontro do ser falante com lalíngua. 
Somente no Seminário XXIII (LACAN, 1975-1976/2005), encontrei uma explicação esclarecedora dessa redefinição do real. Lacan contrapõe a energética freudiana (pulsão de morte) à sua invenção do real. O real redefinido como lalíngua é excluído da linguagem articulada, embora faça parte, como tudo que é humano, do campo do significante. A nomeação do real, a invenção de um significante novo, os efeitos de poesia, os neologismos, circunscrevem o ponto no qual se realiza a conjunção possível entre o simbólico e o real. A língua é viva. Cada ser falante, ao menos potencialmente, pode acrescentar alguma coisa nova ao código com seu dizer. O Nome do pai, desse ponto de vista, não é somente aquele que interdita o gozo, mas é também aquele que sanciona o desvio e autoriza a criação de sentido novo. Com as fórmulas da sexuação, Lacan demonstra que o mito do "assassinato do pai que goza de todas as mulheres” é um fantasma masculino. O pai — como exceção que interdita e submete todo homem ao gozo marcado pela castração — é uma ficção que tem sua origem na experiência do órgão masculino aprisionado entre tumescência e detumescência. É por essa razão que o homem é dividido pela identificação ao significante do Nome do pai e, só pode abordar o objeto causa do seu desejo por meio do objeto fetiche que vela a falta do pênis na mulher. Graças a essa reformulação, o fantasma ( $\$<>$ a) não será mais unissex, pois descreve apenas a estrutura do desejo masculino.

Do lado feminino, "A mulher" não existe, somente existem as mulheres. Como não existe a exceção feminina — isto é, a mulher que causaria o desejo de todos os homens — as mulheres não são divididas pelo significante d’A Mulher. Vale a pena observar que Lacan parece sancionar a enigmática intuição de Freud (1925/1977, p.319-320) de que a mulher não tem um supereu "tão inexorável, tão impessoal e tão independente de suas origens emocionais como exigimos dos homens”. Por essa razão razão, a mulher modelo não existe. Lacan retoma também, eu acredito, outra referência de Freud (1916/1974) sobre o caráter tipicamente feminino: aquele que reivindica ser tratado como exceção. De acordo com as fórmulas lacanianas da sexuação, cada mulher é, ela própria, uma exceção. Se tomamos cada mulher como encarnação da exceção, fica mais fácil compreender por que a palavra da mulher é a prova da verdade que realiza a conjunção entre o semblante e o gozo. É legítimo concluir que a mulher é um dos Nomes do Pai.

A estrutura do desejo feminino não é unificada, por essa razão é mais complexa do que a do homem. Ela deseja o órgão que o falo simboliza no corpo do homem. No lugar do falo, ela somente encontrará o órgão. Ela não deseja o objeto a, mais além do falo. Ela precisa que o homem fale sobre o que ela é, para ele, como objeto a. Para ela, esse gozo que depende da fala é o verdadeiro amor sem limites. Somente no campo do discurso amoroso, uma mulher pode apreender a 
si mesma como objeto a, causa do desejo de um homem. Essa operação discursiva é essencial para que ela consinta em encarnar o objeto a para um homem.

Em seu último ensino, Lacan (1975-1976/2005) retoma a relação do falo com o Nome do pai, promovendo-os à categoria de sintoma. A não-relação entre os sexos não se resolve pela via de uma ética do desejo e sim graças à responsabilidade pelo sintoma. A lei do Pai, nesse novo contexto, é a lei do amor. O amor nasce da responsablidade pela diferença sexual. Não há responsabilidade, segundo Lacan (2005), senão sexual. Por outro lado, não há relação sexual senão quando não há equivalência entre os sexos. Do Nome do pai depende certo saber-fazer para promover a articulação entre os registros. "Não se é responsável, senão na medida de nosso savoir-faire" (LACAN, 1975-1976/2005, p.61). Segue-se que a responsabilidade sexual do homem e da mulher não é a mesma. Uma mulher é para um homem um sinthoma. Um homem é para uma mulher, algo pior que um sintoma, uma aflição. Lacan nos deixa como herança essa difícil lição. O que é preciso, então, para que haja felicidade no amor?

Miller (2006) avança que somente existe satisfação sintomática. O encontro contingente realiza a conjunção entre o sentido e o real. É a novidade do encontro que torna o objeto sexual real, presente e autêntico.

\section{A FELICIDAdE DO SINTOMA: POLÍTICA LACANIANA DA SEXUALIDADE}

Se a relação sexual não existe, a clínica psicanalítica se orienta pela contingência do encontro, isto é, pelo termo que Miller (1998) introduziu: o parceirosinthoma. Essa perspectiva nos leva a colocar no centro do processo analítico, os efeitos do Nome do pai nos destinos da sexuação masculina e feminina. Em minha exposição espero ter podido demonstrar que essa conclusão foi extraída da análise de um deslocamento do problema da sexuação no ensino de Lacan. No início ele propunha uma clínica do sujeito do significante, depois, uma clínica do fantasma unissex e, finalmente, uma clínica da responsabilidade pela solidão, isto é, pela não-equivalência do inconsciente dos seres sexuados. Uma clínica da não-relação sexual é também uma clínica da contingência da relação sexual.

Essa orientação no sentido de conferir consistência e peso sexual às relações amorosas, inclusive à relação do analisando ao seu analista, contraria a tendência das nossas sociedades individualistas e democráticas a uma despersonalização generalizada do Outro. Há uma tendência, como afirma Miller (2003), na civilização contemporânea, ao esvaziamento do peso das relações dissimétricas.

A felicidade, na modernidade, tornou-se uma questão política: “Não poderia haver satisfação de ninguém sem a satisfação de todos” (LACAN, 1959-1960/1986, p.351) O psicanalista surge nesse contexto, pois se oferece para receber uma demanda de felicidade. Em seu Seminário sobre a Ética, Lacan (1959-1960/1986) precisa que essa demanda se estabelece além e aquém dela mesma ao articular- 
se ao significante. A satisfação da necessidade impele a demanda a buscar outra coisa e o desejo se produz nessa brecha como o que suporta essa metonímia, relançando-a mais além de si própria. Todo aquele que deseja, como dizíamos antes, está condenado à permanente insatisfação nessa vida. “É por isso que a questão da realização do desejo se formula necessariamente na perspectiva do Juízo Final” (LACAN, 1959-1960/1986, p.353). A felicidade tornou-se uma questão de política e a renúncia ao gozo é apenas um instrumento para extrair da vida o gozo a mais com o desejo de saber. O sofrimento neurótico é a consequência de sua demanda insaciável de felicidade. Entretanto, o desejo do analista, como ele finalmente reconhece, "não pode ser o desejo de um impossível” (LACAN, 1959-1960/1986, p.360).

A intervenção do analista como parceiro-sinthoma contraria essa tendência a não poder desejar e ser feliz ao mesmo tempo. O desejo do analista, conceito da prática analítica que privilegia o desejo de saber, alimenta a demanda insaciável de felicidade. A intervenção do analista como parceiro-sinthoma, ao contrário, funciona como nó, como oferta do semblante do encontro contingente entre amor e desejo. Esta modalidade de intervenção não aprofunda o vazio, pois sabe que ele é sem fim. Também não aposta numa mesma felicidade para todos e todas, uma vez que reconhece que a diferença sexual engendra a diferença estrutural entre o sintoma do homem e o da mulher. Não se trata de diferença de representações de gênero, mas do real.

Por que Lacan não se refere ao desejo do analista ao final de seu ensino? Podemos ensaiar uma resposta, se consideramos aquilo que Miller (2001a) desenvolve sobre o último ensino de Lacan: o objeto a, causa do desejo, não é o real. O real é sem lei. O real é radicalmente excluído do sentido. O sintoma é a única exceção a essa regra, pois conserva o sentido no real. O sintoma é o ponto irredutível e não o objeto a.

Consequentemente, as intervenções do analista devem promover o encontro contingente entre sentido e o real. $\mathrm{O}$ analista opera como um parceiro-sinthoma suplementar. O analista que foi definido primeiro como "sujeito suposto saber", depois como “objeto causa de uma análise”, agora deve ser alçado à potência do Nome do pai que vivifica o corpo. O Nome do pai não é apenas um operador simbólico. Um pai é sempre encarnado e — na medida que toma uma mulher como objeto causa do seu desejo - confere peso sexual às palavras. Ele é real. O inconsciente, deste ponto de vista, também é real. Talvez, por essa razão, Lacan tenha sido levado a afirmar que: "o psicanalista não pode ser concebido de outra forma senão como um sinthoma. Não é a psicanálise que é um sinthoma, e sim o psicanalista” (LACAN, 1975-1976/2005, p.135).

No último ensino de Lacan, os registros do real, do imaginário e do simbólico são considerados peças avulsas. Ele não supõe mais, como em seu primeiro 
ensino, que a primazia é do simbólico. É preciso esclarecer, entretanto, que o real não é da ordem da energia não vinculada. O real de Lacan é a lalíngua, os significantes puros. Por isso é preciso alguma coisa a mais, um Outro que enlace os registros, levando os significantes a se articularem numa estrutura. O Outro, entretanto, não é mais o Nome do pai simbólico e sim as encarnações do Nome do pai. O inconsciente tomado como real é pura lalíngua, então, ele é sem Outro. Para operar a embreagem mínima do inconsciente de Um ao inconsciente do Outro, a articulação entre S1 e S2, produzindo uma realidade bem sucedida, é preciso franquear o abismo da disjunção entre simbólico e imaginário. Franquear esse abismo é pura magia e demanda sempre um ato de fé. Miller (2006) resume assim esse ponto de vista: "Em contrapartida, se podemos prescindir do Nome do pai, não podemos prescindir do analista."

Penso que essa abordagem renova a potência do amor de transferência, uma vez que o lugar do analista torna-se equivalente ao do Nome de um Pai encarnado, do sinthoma ou do inconsciente enquanto real. O lugar do analista não remete a nada que seja prévio, pois não existe inconsciente transindividual, nem coletivo, nem nenhum sujeito suposto saber, nem nenhum objeto genérico que causaria o desejo. O lugar do analista é sempre inédito, pois não é a psicanálise — sua teoria ou sua práxis - que é um sinthoma, e sim o psicanalista. Para defini-lo desse novo modo, suponho que é preciso ir além de uma ética do desejo em direção a uma ética da responsabilidade pela solidão do inconsciente de cada um. Implica tomar cada ato de fala como essencialmente sem Outro, como um forçamento de um inconsciente particular que pode esperar converter-se em um dizer se ele consegue se enganchar no inconsciente de alguém. Por essa razão, o Outro de cada um é sempre um outro localizado. Ao analista cabe a tarefa de recriar esse atributo paterno que é o poder de surpreender e de envolver o sujeito na experiência analítica.

Sobre o Nome do pai como outro localizado e encarnado, trago uma pontuação de Seminário XXII, RSI:

"um pai não tem direito ao respeito, nem ao amor, se o dito amor, o dito respeito, não for, vocês não vão crer nas minhas orelhas, pai-versamente orientado, quer dizer feito de uma mulher, objeto a que causa seu desejo Mas, aquilo que esta mulher em pequeno a-colhe, se posso me expimir assim, não tem nada a ver com a questão! Aquilo de que ela se ocupa, é de outros objetos a que são as crianças (...)” (LACAN, 1974-1975, p.63)

Uma mulher é um sintoma para um homem. Mas o contrário não é verdade, ela tem seus próprios objetos a: “Uma mulher, tanto quanto um homem não é um objeto a. Ela tem os seus, como eu disse agora mesmo, dos quais ela se ocu- 
pa, isso não tem nada a ver com aquele em cujo desejo particular, ela se apoia" (LACAN, 1974-1975, p.65).

Em seu Seminário XXIII (LACAN, 1975-1976/2005, p.64), esse tema é retomado sob o ângulo da responsabilidade sexual e o Nome do pai: “(...) nesse sentido, em que responsabilidade quer dizer não-resposta ou resposta lateral, não há responsabilidade senão sexual, coisa que todo mundo pressente".

No Seminário RSI, essa responsabilidade sexual é melhor definida, conforme se pode depreender do trecho reproduzido a seguir:

“Aquilo de que ela se ocupa, é de outros objetos a que são crianças, juntos às quais o pai intervém, excepcionalmente, nos casos mais bem sucedidos, para manter na repressão, no justo meio-Deus se vocês me permitem. A versão que lhe é própria de sua perversão, única garantia da sua função de pai, que a função de sintoma tal como a escrevi. Para isso é suficiente que ele seja um modelo da função. Eis o que deve ser o pai, na medida em que ele não pode senão ser exceção, ele não pode ser modelo da função senão por realizar o tipo.” ( LACAN, 1974-1075, p.63)

Devemos a Freud a afirmação de que o pai é o primeiro a se amar nesse mundo. Lacan a retoma, definindo a lei do pai como a lei do amor. O amor do pai é esse nó entre a lei, o desejo e o gozo pulsional. “O complexo de Édipo é enquanto tal um sintoma. É na medida em que Nome do pai é também o Pai do Nome que tudo se sustenta, o que não torna menos necessário o sintoma” (LACAN, 1974-1975).

A relação sexual não existe, entretanto, quando não há equivalência entre os sexos haverá sinthoma, isto é amor! A lei do amor entre os sexualmente diferentes instala, mais além da ética do desejo, a responsabilidade pela solidão falante ou silenciosa na diferença sexual.

"No nível do sinthoma não há, portanto, equivalência sexual, quer dizer que há relação. Com efeito, se a não relação advém da equivalência, é na medida em que não há equivalência sexual que estruture a relação. Haverá ao mesmo tempo, relação sexual e não relação sexual. Ali onde há relação, é na medida que há sinthoma, quer dizer, que o outro sexo se sustenta do sinthoma." (LACAN, 1975-1976/2005, p.101)

No último ensino de Lacan, o Nome do pai é valorizado em duas dimensões: a da sexuação e a da invenção. A primeira coincide com o desejo de um homem por uma mulher que é seu sintoma. A segunda é a do amor ao pai, sintoma dos filhos. A primeira surge com o desejo do homem e introduz a falta, o pecado do pai. É da ordem do complexo de castração e tem a função de transmitir a 
diferença sexual. A outra é menos ligada diretamente ao desejo do homem. O amor ao pai, fundamento do complexo edipiano, é uma suplência e ensina o que fazer com o real irredutível da diferença entre os sexos. Nessa medida, o amor ao pai é uma invenção fundamental para a gênese do ideal do eu, dos semblantes e dos papéis sexuais.

Recebido em 22/12/2008. Aprovado em14/4/2009.

\section{REFERÊNCIAS}

COELHO DOS SANTOS, Tania (2001) Quem precisa de análise hoje?, São Paulo: Bertrand Brasil.

(2005a) Por la ex-sistencia de um significante nuevo! Revista Acheronta de Psicanálise, v.21, Buenos Aires, p.1-15.

\& AZEREDO, F. (2005b) Um tipo excepcional de caráter. Psychê:

Revista de Psicanálise, Ano IX, n.16, São Paulo, dez., p.77-95.

. (2005c) "A prática lacaniana na civilização sem bússola", in

(org.). Efeitos terapêuticos na psicanálise aplicada. Rio de Janeiro:

Contracapa, p.61-92.

—. (2005d) Sinthoma: corpo e laço social, Rio de Janeiro: Sephora/ UFRJ .

O psicanalista é um sinthoma, in: Latusa Revista da EBP/RJ, n.11, p.57-72, 2006.

FREUD, S. (1975/1977) Edição standard das obras psicológicas completas de Sigmund Freud. Rio de Janeiro: Imago.

(1923) “A organização genital da libido”, v.XIX, p.177-186.

(1925) “Algumas consequências psíquicas da distinção anatômica entre os sexos”, v.XIX, p.303-322.

(1924) “A dissolução do complexo de Édipo”, v.XIX, p.215-226.

(1931) “Sexualidade feminina”, v.XXI, p.257-281.

(1933) "Feminilidade”, v.XXII, p.130-165.

(1937) “A análise terminável e interminável”, v.XXIII, p.239-287.

(1930-1929) "Mal-estar na civilização”, v. XXI, p.81-178.

LACAN, J. (1966) Écrits, Paris: Seuil.

(1965-1966/ 1966a) “La science et la verité”, p.855-878.

(1063/1966) "Kant avec Sade”, p.765-792.

(1963-1964/1973) Le Séminaire Livre XI, Les quatre concepts fondamentaux de la psychanalyse, Paris: Seuil.

. (1954-1955/1978) Le Séminaire Livre II, Le moi dans la théorie de Freud

et dans la technique de la psychanalyse, Paris: Seuil.

(1972-1973/1984) Le Séminaire, Livre XX, Encore, Paris: Seuil.

(1959-1960/1986) Le Séminaire, Livre VII, L'éthique de la psychanalyse,

Paris: Seuil.

(1969-1970/ 1991) Le Séminaire, Livre XVII, L'envers de la psychanalyse.

Paris: Seuil. 
(1962-1963/2004) Le Séminaire, Livre X, L’Angoisse, Paris: Seuil. (1975-1976/ 2005) Le Séminaire, Livre XXIII, Le Sinthome. Paris: Seuil,

(1968-1969/2006a) Le Séminaire, Livre XVI, D'un Autre à l'autre. Paris: Seuil.

(1971/2006b) Le Séminaire, Livre XVIII, D’un discours qui ne serait pas du semblant. Paris: Seuil.

(1974-1975) Le Seminaire XXII, RSI, Éditions de l’Association Freudienne Internationale (hors commerce).

MILLER, J. A. (1998) O osso de uma análise, Salvador: Biblioteca Agente.

(1999) Les six paradigmes de la jouissance, in: La Cause Freudienne, n.43, Paris: Navarin Editeur, Seuil, p.7-32.

(1999) Un répartitoire sexuel, in; La Cause Freudienne, n.40, Paris: Navarin Editeur/Seuil, p.7-28.

(2000) Biologie lacanienne et événement de corps, in: La cause freudienne, n.47, Paris: Navarin Editeur, Seuil, p.7-60.

(2001a) Le réel est sans loi, in: La Cause Freudienne, n.49, Paris: Navarin Editeur/Seuil, p.7-20.

(2001b) Psychanalyse pure, psychanalyse appliquée et psychothérapie, in: La Cause Freudienne, n.46, Paris: Navarin Editeur/Seuil, p.7-36.

. (2001c) Quand les semblants vacillent, in: La Cause Freudienne, n.47, Paris: Navarin Editeur/Seuil, p.7-18.

(2002) Le dernier enseignement de Lacan, in: La Cause Freudienne, n.51, Paris: Navarin Editeur/Seuil, p.7-34.

(2002) L'ex-sistence, in: La Cause Freudienne, n.50, Paris: Navarin Editeur/Seuil, p.7-25.

. (2006) Une lecture du Seminaire D'un Autre à l'autre, l'envers de Lacan, in: La Cause Freudienne, n.67, Paris: Navarin Editeur/Seuil, p.99-142.

Tania Coelho dos Santos

taniacs@openlink.com.br 